\title{
A comparative analisys of pelvic floor muscle strength in women with stress and urge urinary incontinence
}

\author{
Monica Orsi Gameiro, Eliane Cristina Moreira, Renata Spagnoli Ferrari, Paulo Roberto Kawano, Carlos \\ Roberto Padovani, João Luiz Amaro
}

Physiotherapy Service (MOG), Department of Urology (RSF, PRK, JLA), and Department of Biostatistics (CRP), School of Medicine, São Paulo State University (UNESP), Botucatu and Physiotherapy Department, Health Sciences Center (ECM), Paraná State University, Londrina, Paraná, Brazil

\section{ABSTRACT}

Aims: To assess pelvic floor muscle (PFM) strength in women with stress urinary incontinence (SUI) and urge urinary incontinence (UUI).

Materials and Methods: 51 women were prospectively divided into two groups, according to the symptoms as SUI $(\mathrm{G} 1=22)$ or UUI $(\mathrm{G} 2=29)$. Demographic data, such as number of pads/ 24 hours, number of micturations/ 24 hours and nocturia, delay time of urgent void (i.e., the time period for which an urgent void could be voluntarily postponed), number of parity and vaginal deliveries were obtained using a clinical questionnaire. Objective urine loss was evaluated by $60-\min$. Pad Test, subjective urine stream interruption test (UST) and visual survey of perineal contraction. Objective evaluations of PFM were performed in all patients (vaginal manometry).

Results: Median of age, mean number of pads / 24 hours, nocturia and warning time were significantly higher in UUI comparing to SUI group. During UST, 45.45\% in G1 and 3.44\%, in G2, were able to interrupt the urine stream ( $p<0.001)$. The $60-\mathrm{min}$. Pad Test was significantly higher in G2 compared to G1 women $(2.7 \pm 2.4$ vs $1.5 \pm 1.9$ respectively, $p=0.049$ ). Objective evaluation of PFM strength was significantly higher in the SUI than in the UUI patients. No statistical difference was observed regarding other studied parameters.

Conclusion: Pelvic floor muscle weakness was significantly higher in women with UUI when compared to SUI.

\section{ARTICLE INFO}

\section{Key words:}

Pelvic Floor; Women; Urinary Incontinence; Stress; Urinary

Incontinence; Urge

Int Braz J Urol. 2012; 38: 661-6

Submitted for publication:

March 06, 2012

Accepted after revision: July 19, 2012

\section{INTRODUCTION}

Stress urinary incontinence (SUI) is considered when involuntary leakage of urine on effort or exertion occurs $(1,2)$. Urge urinary incontinence (UUI) is defined as urinary incontinence (UI) accompanied by urgency (1). This work will be restricted to SUI and UUI.

Urinary incontinence may involve important psychosocial implications; there is a significant greater proportion of patients (60\%) with urge incontinence with previous history of depression than those with SUI (14\%) (3).

Pelvic floor muscle (PFM) function evaluation may play an important role in the diagnosis and treatment of female urinary incontinence. Amaro et al. reported significant decreased in PFM strength on incontinent women when compared with continent ones (4), showing that the anatomical and functional dete- 
riorations of these striated muscles may cause urinary and fecal incontinence. Vaginal delivery causes several degrees of PFM and connective tissue damage (5). The recovery of these muscles could be therapeutic (6). Some authors observed a positive correlation between increase in PFM strength and improvement in SUI and quality of life (7-10).

Pelvic floor muscle evaluation can be performed using objective and subjective parameters. However, there is no consensus about the best clinical assessment of this muscle (11).

Kegel (12) was the first to describe the perineometer using an endovaginal probe to evaluate the pelvic floor muscle contraction.

Morked (13) et al. demonstrated that continent women had significant higher maximal vaginal squeeze pressure and muscle thickness increment compared with incontinent women.

Visual inspection and digital tests are easy and reliable methods by which insight can be gained into the multi-muscular activity and coordination of the PFM and lower abdominal muscles in continent and incontinent women (14). Lynch and Aronoff (15), in a small sample size, observed better agreement using the tampon scale than the digital scale. Several approaches for evaluating PFM have been described, but without documented validation.

Measurement of PFM function and strength is important in analyzing which is the best training protocol to use, and may be an important tool to provide biofeedback and motivation throughout the training period.

The aim of this study was to assess pelvic floor muscle function and its correlation with SUI and UUI.

\section{MATERIALS AND METHODS}

Fifty one women were prospectively distributed into two groups. Group G1 $(n=22)$ included women with SUI and Group G2 (n = 29), with UUI. Urodynamic studies were not realized for any patient; they were selected using a non validated questionnaire which classified the responders as UUI patients that were not able to postpone the urgency time period in more than
15 minutes. Patients were classified as SUI when ordinary movements such as coughing, walking etc, caused urine leakage. This study was approved by the Bioethics Commission of the Paraná State University.

Demographic data, such as daily fluid intake, number of pads and micturations for 24 hours (24-hour voiding diary), delay time of urgent void (i.e., the time period for which an urgent void could be voluntarily postponed), visual analog scale (VAS) (3) for assessing the level of degree of wetness and discomfort sensation, number of parity and vaginal deliveries were obtained using a clinical questionnaire (3).

Subjective assessment consisted of urinary stream interruption test (UST) and visual analysis of perineal muscle contractions. The patients were evaluated in supine position with a pillow under their head, straight knees and legs abducted. The PFM contractions were evaluated as present or absent depending on visualization.

Objective urine loss was evaluated by the 60-min. pad test $(4,16)$.

Objective evaluation of perineal muscle strength was made using a portable perineometer (Peritron 9300+) connected to a balloon catheter, size $11 \times 2.6 \mathrm{~cm}$, inserted into the vagina. The balloon was located $1 \mathrm{~cm}$ from the outside of vaginal conduit, positioning the middle of the balloon $3.5 \mathrm{~cm}$ inside the introitus vagina $(4,6)$. Measurement of maximum and mean squeeze pressure, and holding period in seconds were assessed in supine position. Only contractions with simultaneous visible inward movement of the perineum were accepted as correct. All evaluations were assessed by a single physiotherapist.

\section{Statistical Analysis}

Analysis of the association between incontinent groups (SUI and UUI) and PFM contraction was performed by the Goodman's test with multinomial distribution (17).

Perineum muscle force comparison was made by Student $\mathrm{T}$ test for independent samples (17). Differences were considered significant for $\mathrm{p}$ value $<0.05$ 


\section{RESULTS}

The average age of UUI patients was significantly higher than the SUI ones (54 yrs. vs. 45 yrs. respectively, $\mathrm{p}<0.05$ ).

The daily fluid intake was significantly lower in UUI group than in SUI (Table-1).

UUI patients had to use a significantly higher number of 24 hours pads when compared to SUI group (Table-1).

Regarding the average number of micturitions in 24 hours, there was no statistical difference between groups (Table-1). However, nocturia was significantly higher in UUI patients (Table-1).

The average delay time of urgent void was significantly lower in UUI than in SUI group (Table-1).

In VAS, the dry perception was significantly lower in UUI patients compared to SUI ones (38\% vs. $68 \%$ respectively, $p=0.04$ ). The discomfort sensation was significantly higher in the UUI group than SUI (76\% vs. 50\% respectively, $p=0.05$ ).

There was no statistical difference between groups considering body mass index, number of parities and vaginal deliveries (Table-1).
The number of patients who were able to interrupt the urinary stream was significantly higher in SUI group (Table-2).

There was no statistical difference between both groups in the visual analysis of perineal muscle contractions (Table-3).

PFM strength was significantly higher in the SUI group (Table-4).

\section{DISCUSSION}

We observed that women were significantly older in the UUI. Other authors have observed more prevalent overactive bladder during the aging process, that could be considered an important factor in urgency genesis $(18,19)$.

In our series, the fluid intake was significantly lower in UUI group, this demonstrates that these women may have attempted to decrease the fluid ingestion to avoid urinary leak due to urgency as self-treatment. Other authors (20) reported that avoiding excessive fluid intake can contribute to reduce the UUI symptoms in women taking anticholinergic medications; however, additional individualized instructions along with other be-

Table 1 - Population characteristics of patients with stress urinary incontinence (SUI) $(n=22)$ and urgency urinary incontinence (UUI) $(\mathrm{n}=29)$.

\begin{tabular}{lccc}
\hline Variable & & Group & Statistical Results ( $\mathrm{p}$ - value) \\
\hline & SUI (G1) & UUI (G2) & $p=0.373$ \\
\hline Body Mass Index & $27.3 \pm 3.7$ & $28.6 \pm 5.5$ & $p=0.041$ \\
Daily Fluid Intake (I) & $1.8 \pm 0.7$ & $1.3 \pm 0.5$ & $p=0.004$ \\
Number of Pads / 24 Hours & $3.0 \pm 1.5$ & $5.0 \pm 2.5$ & $p=0.236$ \\
Micturations / 24 Hours & $6.1 \pm 1.2$ & $6.7 \pm 1.8$ & $p=0.010$ \\
Nocturia & $0.9 \pm 0.9$ & $1.7 \pm 0.9$ & $p<0.001$ \\
Delay time of urgent void (min) & $20.1 \pm 12.2$ & $2.1 \pm 2.2$ & $p=0.691$ \\
Number of parity & $5.9 \pm 2.9$ & $5.5 \pm 2.6$ & $p=0.551$ \\
Vaginal deliveries & $4.4 \pm 2.8$ & $3.9 \pm 2.0$ & $p=0.049$
\end{tabular}


Table 2 - Assessment of pelvic floor performance with stream interruption test expressed in proportional value.

\begin{tabular}{|c|c|c|c|}
\hline \multirow[t]{2}{*}{ Group } & \multicolumn{2}{|c|}{$\begin{array}{l}\text { Proportion of patients with capacity to interrupt the } \\
\text { urinary stream }\end{array}$} & \multirow[t]{2}{*}{ Total } \\
\hline & YES & NO & \\
\hline G1 & $45.45 \%(10)$ & $54.55 \%(12)$ & $100 \%(22)$ \\
\hline G2 & $3.44 \%(1)$ & $96.56 \%(28)$ & $100 \%(29)$ \\
\hline Statistical Results (p-value) & $\mathrm{p}<0.001$ & $p<0.001$ & \\
\hline
\end{tabular}

Table 3 - Visual analysis of perineal muscle contractions.

\begin{tabular}{lccc}
\hline Group & \multicolumn{2}{c}{ Contraction } & Total $(\mathrm{n})$ \\
\hline & Absent $(\mathrm{n} / \%)$ & Present $(\mathrm{n} / \%)$ & \\
\cline { 2 - 3 } $1(\mathrm{SUI})$ & $5(22.7 \%)$ & $17(77.3 \%)$ & 22 \\
$2(\mathrm{UUI})$ & $8(27.6 \%)$ & $21(72.4 \%)$ & 29 \\
\hline
\end{tabular}

$x^{2}=0.16(p=0.69)$

Table 4 - Perineometer evaluation of perineal muscle strength.

\begin{tabular}{lcccc}
\hline Group & \multicolumn{3}{c}{ Perineometer } & Total \\
\hline & $\begin{array}{c}\text { Maximum Peak } \\
\left(\mathrm{cm} \mathrm{H}_{2} \mathrm{O}\right)\end{array}$ & $\begin{array}{c}\text { Mean Peak } \\
\left(\mathrm{cm} \mathrm{H}_{2} 0\right)\end{array}$ & Duration (S) \\
\cline { 2 - 4 } $1(\mathrm{SUI})$ & $26.50 \pm 3.00$ & $16.56 \pm 1.19$ & $9.54 \pm 0.18$ & 22 \\
$2(\mathrm{UUI})$ & $21.70 \pm 0.79$ & $13.72 \pm 0.56$ & $8.43 \pm 0.42$ & 29 \\
Statistical results & $p<0.001$ & $p<0.001$ & $p<0.001$ & \\
\hline
\end{tabular}

havioral therapies did little to further outcome improvement. It shows that little is known about the effect of fluid management in women with UUI. Despite this, some authors (21) have proposed to reduce bladder irritants such as acid food, alcohol, and caffeine which may decrease the number of UI episodes in patients with overactive bladder.

As for number of pads/24 hours, nocturia, delay time of urgent void, VAS to wetness sensation and discomfort, we observed worse results in UUI group, demonstrating that urgency may affect peo- ple's daily routine. Stewart et al. (22) observed that UUI is bothersome and is associated with decrease of quality of life. UUI patients may also change their behavior such as prophylactic urination and fluid restriction. Incontinence episodes have also shown to be perceived by women as a barrier to perineal exercises (23).

The urine stream interruption test (UST) is considered an objective method to quantify pelvic floor muscle strength (4). Using UST to assess contraction ability and pelvic floor muscle strength, we 
observed that only $1 \%$ of UUI patients and $45 \%$ of SUI women were able to interrupt the urine stream. This suggested that women with urge incontinence may have a lower perception and strength of pelvic floor muscle. Amaro et al. (4), studying the effects of UST in incontinent patients in a control trial, concluded that incontinent women also have a lower perception of PFM, demonstrating that the strength of perineal muscle during exercises can also be used as rehabilitation treatment of SUI and UUI women.

The visual analysis of perineal muscle contractions showed no statistical difference between groups, what may demonstrate the ineffectiveness of this modality of PFM evaluation, whereas the perineometer test presented a significant deficit of muscular strength in the UUI group compared to the SUI one. Despite this, Deveuse et al. (14) observed that visual inspection and digital test are easy and reliable methods to evaluate PFM strength.

Women with weakness in perineal muscles were unable to effectively contract their PFM to inhibit detrusor contractions. This fact may inactivate the mechanism that provides negative feedback worsening the urgency symptoms (24). In our study, the pelvic floor muscle weakness was significantly higher in women with UUI when compared to SUI. This demonstrated that the status of the levator ani muscle can be important to functional and objective evaluation of pelvic floor muscle to assess UUI and SUI patients.

\section{CONFLICT OF INTEREST}

None declared.

\section{REFERENCES}

1. Abrams P, Cardozo L, Fall M, Griffiths D, Rosier P, Ulmsten $U$, et al.: The standardisation of terminology in lower urinary tract function: report from the standardisation sub-committee of the International Continence Society. Urology. 2003; 61: 37-49.

2. Abrams P, Andersson KE, Birder L, Brubaker L, Cardozo $\mathrm{L}$, Chapple $\mathrm{C}$, et al.: Fourth International Consultation on Incontinence Recommendations of the International Scientific Committee: Evaluation and treatment of urinary incontinence, pelvic organ prolapse, and fecal incontinence. Neurourol Urodyn. 2010; 29: 213-40.
3. Zorn BH, Montgomery H, Pieper K, Gray M, Steers WD: Urinary incontinence and depression. J Urol. 1999; 162: 82-4.

4. Amaro JL, Moreira EC, De Oliveira Orsi Gameiro M, Padovani CR: Pelvic floor muscle evaluation in incontinent patients. Int Urogynecol J Pelvic Floor Dysfunct. 2005; 16: 352-4.

5. DeLancey J0: Structural aspects of the extrinsic continence mechanism. Obstet Gynecol. 1988; 72: 296-301.

6. Amaro JL, Oliveira Gameiro MO, Padovani CR: Treatment of urinary stress incontinence by intravaginal electrical stimulation and pelvic floor physiotherapy. Int Urogynecol J Pelvic Floor Dysfunct. 2003; 14: 204-8; discussion 208.

7. Bø K: Pelvic floor muscle strength and response to pelvic floor muscle training for stress urinary incontinence. Neurourol Urodyn. 2003; 22: 654-8.

8. Fitz FF, Costa TF, Yamamoto DM, Resende AP, Stüpp L, Sartori MG, et al.: Impact of pelvic floor muscle training on the quality of life in women with urinary incontinence. Rev Assoc Med Bras. 2012; 58: 155-9.

9. Da Roza T, de Araujo MP, Viana R, Viana S, Jorge RN, Bø K, et al.: Pelvic floor muscle training to improve urinary incontinence in young, nulliparous sport students: a pilot study. Int Urogynecol J. 2012; 23: 1069-73.

10. Nascimento-Correia G, Santos-Pereira V, Tahara N, Driusso $P$ : Effects of pelvic floor muscle training on quality of life of a group of women with urinary incontinence: randomized controlled trial. Actas Urol Esp. 2012; 36: 216-21.

11. Sartore A, Pregazzi R, Bortoli P, Grimaldi E, Ricci G, Guaschino $S$ : The urine stream interruption test and pelvic muscle function in the puerperium. Int J Gynaecol Obstet. 2002; 78: 235-9.

12. Kegel AH: Progressive resistance exercise in the functional restoration of the perineal muscles. Am J Obstet Gynecol. 1948; 56: 238-48.

13. Mørkved S, Salvesen KA, Bø K, Eik-Nes S: Pelvic floor muscle strength and thickness in continent and incontinent nulliparous pregnant women. Int Urogynecol J Pelvic Floor Dysfunct. 2004; 15: 384-9; discussion 390.

14. Devreese A, Staes F, De Weerdt W, Feys H, Van Assche A, Penninckx $F$, et al.: Clinical evaluation of pelvic floor muscle function in continent and incontinent women. Neurourol Urodyn. 2004; 23: 190-7.

15. Lynch CM, Aronoff CK: Reproducibility of grading scales of pelvic muscle strength: standard versus tampon scale. Int Urogynecol J Pelvic Floor Dysfunct. 2003; 14: 288-90; discussion 290.

16. Laycock J, Green R: Interferential therapy in the treatment of incontinence. Physiotherapy 1988; 74: 161-68.

17. Goodman LA: Simultaneous confidence intervals for multinomiais proportions. Technometrics. 1965; 7: 247-54.

18. Stewart WF, Van Rooyen JB, Cundiff GW, Abrams P, Her$\operatorname{zog} A R$, Corey $R$, et al.: Prevalence and burden of overactive bladder in the United States. World J Urol. 2003; 20: 327-36. 
19. Staskin DR: Overactive bladder in the elderly: a guide to pharmacological management. Drugs Aging. 2005; 22: 1013-28.

20. Zimmern P, Litman HJ, Mueller E, Norton P, Goode P; Urinary Incontinence Treatment Network. Effect of fluid management on fluid intake and urge incontinence in a trial for overactive bladder in women. BJU Int. 2010; 105: 1680-5.

21. Ubee SS, Manikandan R, Singh G: Medical management of overactive bladder. Indian J Urol. 2010; 26: 270-8.

22. Stewart WF, Van Rooyen JB, Cundiff GW, Abrams P, Herzog AR, Corey $R$, et al.: Prevalence and burden of overactive bladder in the United States. World J Urol. 2003; 20: 327-36.

23. Nygaard I, Girts T, Fultz NH, Kinchen K, Pohl G, Sternfeld $\mathrm{B}$ : Is urinary incontinence a barrier to exercise in women? Obstet Gynecol. 2005; 106: 307-14.
24. Kenton K, Brubaker L: Relationship between levator ani contraction and motor unit activation in the urethral sphincter. Am J Obstet Gynecol. 2002; 187: 403-6.

Correspondence address: Dr. João Luiz Amaro Department of Urology School of Medicine, São Paulo State University (UNESP), Botucatu Botucatu, São Paulo, 18618-970, Brazil Telephone: + 5514 3811-6271 E-mail: jamaro@fmb.unesp.br 